\title{
Cadmium Removal Performances of Different Dye Ligands Attached Cryogel Disks
}

\author{
Burak Keleş, ${ }^{a}$ Tülden Inanan, ${ }^{b}$ Nalan Tüzmen, ${ }^{\mathfrak{c}, *}$ and Adil Denizli ${ }^{d}$ \\ ${ }^{a}$ Dokuz Eylul University, The Graduate School of Natural and Applied Sciences, Izmir, Turkey \\ ${ }^{\mathrm{b}}$ Department of Chemistry, Faculty of Science and Arts, Aksaray University, Aksaray, Turkey \\ 'Department of Chemistry, Faculty of Science, Dokuz Eylul University, Izmir, Turkey \\ ${ }^{\mathrm{d} D e p a r t m e n t ~ o f ~ C h e m i s t r y, ~ F a c u l t y ~ o f ~ S c i e n c e, ~ H a c e t t e p e ~ U n i v e r s i t y, ~ A n k a r a, ~ T u r k e y ~}$
}

RECEIVED SEPTEMBER 26, 2014; REVISED FEBRUARY 20, 2015; ACCEPTED APRIL 14, 2015

\begin{abstract}
Poly(HEMA) cryogel disks were synthesized by free radical polymerization of 2-hydroxyethylmethacrylate (HEMA), and then Cibacron Blue F3GA (CB), Reactive Green 19 (RG) and Congo Red (CR) were immobilized as dye ligands. Disks were characterized by Fourier transform infrared spectroscopy (FTIR), scanning electron microscope (SEM) and swelling degree, porosity calculations. $\mathrm{Cd}^{2+}$ adsorption experiments were performed for $60 \mathrm{~min}$. Maximum adsorption capacities were determined as $25.5 \mathrm{mg} / \mathrm{g} ; 48.0 \mathrm{mg} / \mathrm{g}$ and $28.5 \mathrm{mg} / \mathrm{g}$ at $\mathrm{pH}=7.0$ for poly(HEMA)-CB; poly(HEMA)-RG and poly(HEMA)-CR, respectively. Langmuir isotherm fitted best with the adsorption data and adsorption thermodynamics showed that $\mathrm{Cd}^{2+}$ adsorption is thermodynamically favorable and a physisorption process. A great majority of adsorbed $\mathrm{Cd}^{2+}$ desorbed with $1 \mathrm{M} \mathrm{NaCl}$ and cryogel disks can be re-used in adsorption experiments. $\mathrm{Cd}^{2+}$ removal efficiencies of disks from human plasma are approximately $45 \%$. Dyeattached cryogel disks synthesized in this study have potential in use for environmental and therapeutic applications.
\end{abstract}

Keywords: $\mathrm{Cd}^{2+}$ removal, cryogel disks, dye ligands, adsorption isotherms, kinetic

\section{INTRODUCTION}

Although it is pointed out that metals play important roles in biological processes and some of them are classified as essential, toxic symptoms are exhibited above threshold levels of metal ions. ${ }^{1}$ Heavy metals, known as teratogenic and carcinogenic, can be bioaccumulated by vegetables, hydrophytes and aquatic inhabitants and, finally enriched by human beings through food chains. ${ }^{2,3}$ Unlike organic toxicants, heavy metals are not appropriate to biological degradation. ${ }^{4}$ Cadmium, which is highly toxic to human, plants and animals even at low concentrations, has been classified by US Environmental Protection Agency as a probable human carcinogen. ${ }^{2}$ It has an extremely long biological half-life and causes kidney damage, altered renal tubular function, impaired regulation of calcium and phosphorus, bone demineralization, osteomalacia, and pathological fractures. ${ }^{5}$ It also causes liver and lung damage. ${ }^{6}$ Men may become exposed to cadmium due to its use in electroplating, smelting, plastics, pigments, ceramics, battery, cadmium-rich phosphate fertilizers and mining. ${ }^{3,6}$ Cadmium concentration in blood of healthy person is $0.01 \mathrm{mg} / \mathrm{L}$ and it is excreted in the urine. Cadmium concentration above $0.05 \mathrm{mg} / \mathrm{L}$ is a strong sign of cadmium intoxication due to excessive exposures to external cadmium sources. ${ }^{5,7}$ To date there are no proven effective treatments for chronic cadmium intoxication. Besides supportive therapy and hemodialysis, metal poisoning is often treated with a chelating agent. ${ }^{8}$ Different chelating agents that are available commercially for the treatment of cadmium poisoning are British anti lewisite and calcium disodium EDTA. Recently, one of the most promising techniques for blood detoxification is extracorporeal affinity adsorption. So far, only a few affinity adsorbents were reported for metal detoxification. ${ }^{9-13}$

Polymeric materials are suitable candidates due to their reactive functional groups, good mechanical properties, ease of preparation method and applicability to introduce bio-friendly components for improving biocompatibility. ${ }^{14}$ Polymeric gels have applications in many different areas of biotechnology. ${ }^{15}$ One of the new types of polymer gels with considerable potential in biotechnology is 'cryogels'. ${ }^{16}$ Several advantages of cryogels are large pores, short diffusion path, low pressure drop, and very short residence time for both ad-

\footnotetext{
* Author to whom correspondence should be addressed. (E-mail: nalan.tuzmen@deu.edu.tr)
} 
sorption and elution. Cryogels are also cheap materials and they can be used as disposable avoiding cross contamination between batches. Furthermore, cryogels can be formed in any desirable shape, for example, blocks, cylinders, tubes, granules and disks. ${ }^{16}$

A number of textile dyes, known as reactive dyes, have been used in dye-ligand affinity systems. Dyes are commercially available, inexpensive and can be easily immobilized, especially on matrices bearing hydroxyl groups. Most of the reactive dyes consist of a chromophore, linked to a reactive group (often a mono- or dichlorotriazine ring). They also have sulfonic acid groups to provide the desired solubility of the molecule in aqueous media. Some dyes contain carboxyl, amino, chloride, or metal complexing groups; most contain nitrogen both in or outside on aromatic ring. ${ }^{17}$

The aim of this work was to evaluate the performances of cryogel disks with different dye ligands for cadmium removal from aqueous solutions and to determine their efficiencies for $\mathrm{Cd}^{2+}$ removal from human plasma.

\section{EXPERIMENTAL}

\section{Materials}

HEMA ( $\geq 99 \%$ ), $N, N, N^{\prime}, N^{\prime}$-tetramethylethylenediamine (TEMED, more than $99 \%$ ) and amoniumpersulfate (APS, $\geq 98 \%$ for electrophoresis) were supplied by Fluka (Fluka A.G. (Buchs, Switzerland). N,N'-methylene-bis(acrylamide, $99 \%$ ) (MBAAm), sodium chloride $(99 \%)$ and cadmium sulfate $(\geq 99.0 \%)$ were obtained from Sigma (St Louis, USA). All other chemicals were of the highest purity commercially available and were used without further purification. All water used in the adsorption experiments was purified using a Millipore S.A.S 67120 Molsheim-France facility whose quality management system is approved by an accredited registering body to the ISO 9001. Before use the laboratory glassware was rinsed with deionised water and dried in a dust-free environment.

\section{Preparation of Poly(HEMA) Cryogel Disks}

For the purpose of cadmium removal, poly(HEMA) cryogel disks were synthesized by free radical polymerization started with TEMED and APS. A typical preparation procedure was given as follows: $21.43 \mathrm{mmol}$ HEMA was mixed with MBAAm solution $(3.67 \mathrm{mmol}$ in $20 \mathrm{~mL}$ ). The cryogel was then produced by free radical polymerization initiated by TEMED and APS. After adding APS $(0.175 \mathrm{mmol})$, the solution was cooled in an ice bath for 2-3 min. TEMED $(0.335 \mathrm{mmol})$ was added and the reaction mixture was stirred for $1 \mathrm{~min}$. Then, the reaction mixture was poured between two glass plates separated with $1.5 \mathrm{~mm}$ thick spacers. The polymerization mixture was frozen at $-16{ }^{\circ} \mathrm{C}$ for $24 \mathrm{~h}$ and then thawed at room temperature. Poly(HEMA) cryogel disks were washed with $2 \mathrm{~L}$ water to remove unreacted monomers. The cryogel was cut into circular disks $(0.8 \mathrm{~cm}$ in diameter) and mass of cryogel disks was determined over a range of 20-25 mg. Cryogel disks stored in buffer containing $0.02 \%$ sodium azide at $4{ }^{\circ} \mathrm{C}$ until use.

\section{Immobilization of Dye Ligands onto the Poly(HEMA) Cryogel Disks}

Immobilization procedures of CB, RG and CR (Figure 1) were performed using the book of immobilized affinity ligand techniques. ${ }^{18}$ Poly(HEMA) disks were divided into three parts. Every part of disks was bottled up into dye solutions ( $100 \mathrm{mg}$ dye dissolved in $30 \mathrm{~mL}$ deionized water). After shaking at $150 \mathrm{rpm}$ for $30 \mathrm{~min}$ at $60^{\circ} \mathrm{C}, 1.5$ $\mathrm{g} \mathrm{NaCl}$ was added to reaction mixture and shaked $1 \mathrm{~h}$ more. Then, temperature was increased to $70{ }^{\circ} \mathrm{C}$ and $0.15 \mathrm{~g} \mathrm{Na}_{2} \mathrm{CO}_{3}$ added. After $2 \mathrm{~h}$ shaking, reaction mixture was cooled to room temperature and disks were washed with water until washing water was colorless. Dye immobilization processes were checked by UVabsorbance measurements of dyes with using a UVspectrophotometer (Schimadzu 1601, Japan). Finally, disks were washed with ethanol-water (50:50) solution until washing solutions have no UV-absorbance and $\mathrm{CB}$, $\mathrm{RG}$ and CR-attached cryogel disks were stored at $4{ }^{\circ} \mathrm{C}$ until use.

\section{Characterization of the Poly(HEMA) Cryogel Disks}

To determine the swelling degree of the disks $(S)$, disks were dried to constant mass at vacuum oven at $55{ }^{\circ} \mathrm{C}$ and $100 \mathrm{mbar}$ and masses of dried pellets were determined ( $\left.m_{\text {dried disk }}\right)$. The dried disks were bottled up to 50 $\mathrm{mL}$ ionized water and masses of swollen disks were determined ( $\left.m_{\text {swollen disk }}\right)$.
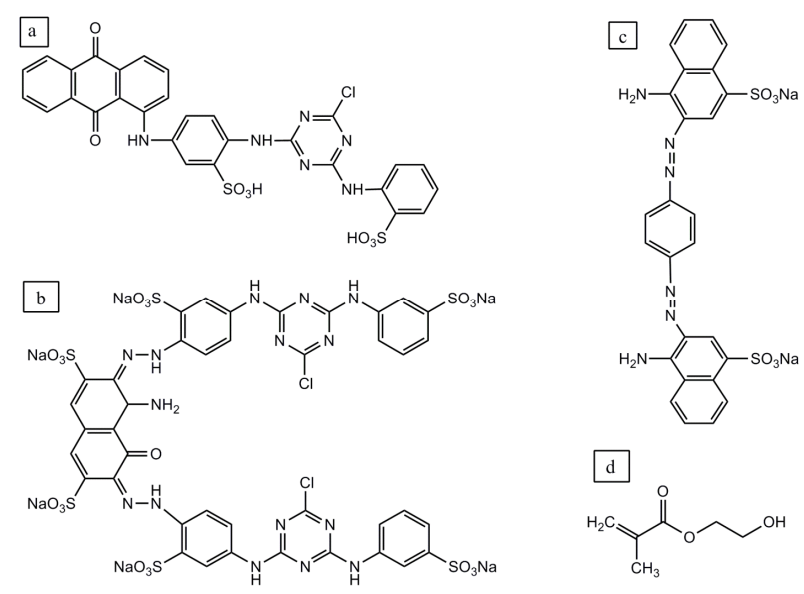

Figure 1. Chemical structure of CB (a), RG (b) and CR (c) and HEMA (d). 
The swelling degree was calculated as:

$$
S=\frac{m_{\text {swollen disk }}-m_{\text {dried disk }}}{m_{\text {dried disk }}}
$$

The water content of cryogel disks were determined according to the studies of Plieva et al., and Horak et al. ${ }^{19,20,21}$ Dried disks were mounted into chamber saturated with water vapor. Water vapor adsorbed onto cryogel disk by time was determined and then weight of cryogel disks adsorbed water vapor was measured ( $m_{\text {water bound disk }}$. Sponge like cryogel disks were squeezed by hand without damaging their physical forms and weight of squeezed disks were determined ( $\left.m_{\text {squeezed disk }}\right)$. The porosity $(P$, expressed in $\%)$ and porosity for macropores $\left(P_{\text {macropores, }}\right.$ expressed in $\left.\%\right)$ were also calculated as follows:

$$
\begin{aligned}
& P=\frac{m_{\text {swollen disk }}-m_{\text {water bound disk }}}{m_{\text {swollen disk }}} \times 100 \\
& P_{\text {macropores }}=\frac{m_{\text {swollen disk }}-m_{\text {squeezed disk }}}{m_{\text {swollen disk }}} \times 100
\end{aligned}
$$

The surface morphology of the poly(HEMA) cryogel disks was examined using SEM. The samples were initially dried in air at $25{ }^{\circ} \mathrm{C}$ for 7 days before being analyzed. A fragment of the dried disk was mounted on a SEM sample mount and was sputter coated for $2 \mathrm{~min}$. The sample was then mounted in a SEM (Phillips, XL30S FEG, Germany). The surface of the sample was then scanned at the desired magnification to study the morphology of the disks.

FTIR spectra of poly(HEMA) cryogel disk and $\mathrm{CB}, \mathrm{RG}$ and CR-attached poly(HEMA) cryogel disks were obtained by using a FTIR spectrophotometer (Perkin Elmer spectrum 100 FT-IR spectrometer) with universal ATR sampling accessory.

\section{Cadmium Adsorption Studies from Aqueous Solution}

Cadmium adsorption studies were performed in a batch system at $25{ }^{\circ} \mathrm{C}$ with stirring continuously. Some variables such as time, $\mathrm{pH}$, initial cadmium concentration and temperature were studied to optimize adsorption conditions. To determine effect of time, adsorption was completed at different time periods. Cadmium solutions were prepared in universal buffer between $\mathrm{pH} 3.0-8.0$ to observe the effect of $\mathrm{pH}$ on the $\mathrm{Cd}^{2+}$ adsorption. Different initial $\mathrm{Cd}^{2+}$ concentrations $(10-500 \mathrm{mg} / \mathrm{L})$ were used to determine the effect of initial $\mathrm{Cd}^{2+}$ concentration and temperature was changed between $15^{\circ} \mathrm{C}$ and $45^{\circ} \mathrm{C}$. The amount of adsorbed $\mathrm{Cd}^{2+}$ per unit mass of the disk $(q)$ was calculated by using the following expression:

$$
q=\frac{c_{0}-c_{e}}{m_{\text {disks }}} V
$$

Where $q$ is adsorption capacity (in $\mathrm{mg} / \mathrm{g}$ ), $c_{0}$ and $c_{\mathrm{e}}$ are the concentration of $\mathrm{Cd}^{2+}$ in the initial solution and in the aqueous phase after treatment for certain period of time, respectively (in $\mathrm{mg} / \mathrm{L}$ ), $V$ is the volume of $\mathrm{Cd}^{2+}$ solution (in $\mathrm{L}$ ) and $m_{\mathrm{disks}}$ is the mass of disks used (in g).

Adsorption experiments were conducted for 60 min which was the equilibrium period. Initial and final cadmium concentrations were determined by Atomic Adsorption Spectrophotometer (AAS) (Perkin-Elmer AA 700).

\section{Desorption and Reusability Studies}

Desorption efficiencies of different agents at various concentrations were investigated. $\mathrm{NaCl}, 2$-mercaptoethanol and thiourea were used as desorption agents and desorption ratios were calculated from the amount of $\mathrm{Cd}^{2+}$ adsorbed and the final metal concentration in the desorption medium. $\mathrm{Cd}^{2+}$ adsorbed disks were placed within the desorption medium containing 0.5-1.0 M $\mathrm{NaCl}, 0.5-1.0 \mathrm{M}$ 2-mercaptoethanol and 0.5-1.0 M thiourea at room temperature for $6 \mathrm{~h}$. It must be pointed out that there was no $\mathrm{CB}, \mathrm{RG}$ and $\mathrm{CR}$ release in this case which shows that dye-molecules are bonded strongly to poly(HEMA) cryogel disks.

After desorption process, disks were washed with water several times and re-conditioned with universal buffer of $\mathrm{pH}=7.0$. These disks were used in $\mathrm{Cd}^{2+}$ adsorption-desorption cycle to test the reusability of dyeattached cryogel disks.

\section{$\mathrm{Cd}^{2+}$ Ions Removal from Human Plasma}

Removal of $\mathrm{Cd}^{2+}$ ions from human plasma was carried out in a batch system. Human blood is collected from thoroughly controlled voluntary blood donors. Human blood was collected into EDTA-containing vacutainers without adding preservatives and red blood cells were separated by centrifugation at $4000 \mathrm{rpm}$ for $30 \mathrm{~min}$ at room temperature, then filtered ( $3 \mu \mathrm{m}$ Sartorius filter) and frozen at $-20{ }^{\circ} \mathrm{C}$. Before use, plasma was thawed for $1 \mathrm{~h}$ at $37^{\circ} \mathrm{C}$ and samples were prepared with different dilutions. Then, adsorption studies were performed with the overloaded plasma samples by using the same procedure mentioned above.

\section{RESULTS AND DISCUSSION}

\section{Characterization of the Dye-Attached Poly(HEMA) Cryogel Disks}

The scanning electron micrograph of the internal structure of the poly(HEMA) cryogel disks is shown in 


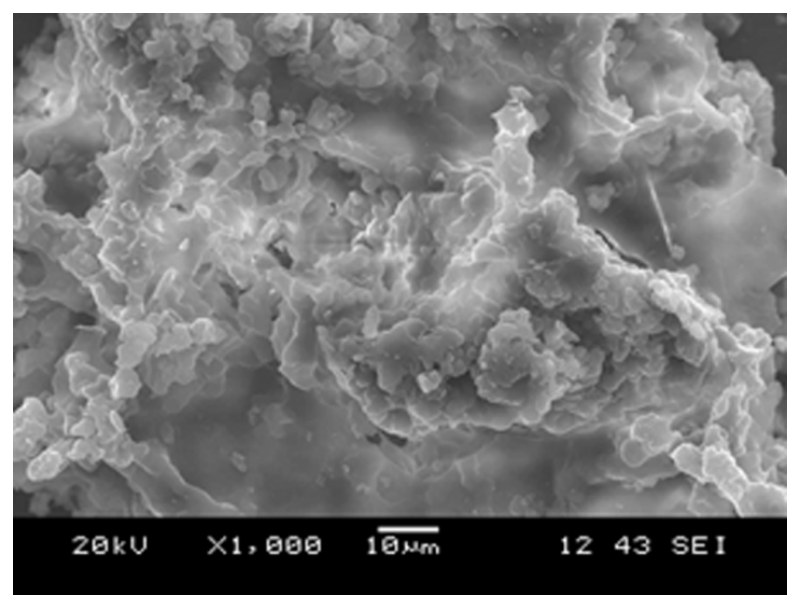

Figure 2. SEM micrographs of poly(HEMA) cryogel disks.

Figure 2, from which it can be seen that dye attached $\mathrm{p}$ (HEMA) cryogel disks have a porous structure and thin polymer walls, with large continuous interconnected pores that provide channels through which the mobile phase can flow.

$\mathrm{CB}, \mathrm{RG}$ and $\mathrm{CR}$ dye ligands were immobilized onto poly(HEMA) cryogel disks. The functional hydroxyl groups on the surface of the pores in the $\mathrm{p}$ (HEMA) cryogel disks produced by polymerization in the frozen state of the HEMA in the presence of APS/TEMED as an initiator/activator pair allowed their modification with dye ligands. The FTIR spectra of the poly (HEMA) and dye-attached poly(HEMA) cryogel disks are shown in Figure 3.

The FTIR bands of dye attached poly(HEMA) cryogel disks have vibration bands around $1055 \mathrm{~cm}^{-1}$ and $1075 \mathrm{~cm}^{-1}$. These bands correspond to $-\mathrm{S}=\mathrm{O}$ stretching and $-\mathrm{SO}_{3} \mathrm{H}$ stretching vibrations, respectively. The presence of aromatic $\mathrm{C}=\mathrm{C}$ stretching vibration band as a shoulder in the spectra of dye attached poly(HEMA) cryogel disks indicated the immobilization of dyes onto poly(HEMA) cryogel disk. -OH stretching band of poly(HEMA) was located in 3312 $\mathrm{cm}^{-1}$. Immobilization of dyes broadened the $-\mathrm{OH}$ stretching band because of the presence of -NH stretching vibrations. Additionally, visual observations (the colors of the cryogel disks) ensured the attachment of $\mathrm{CB}, \mathrm{RG}$ and $\mathrm{CR}$.

Dye-attached cryogel disks were sponge like and elastic. These can be easily compressed by hand to remove water accumulated inside the pores. When compressed cryogel disks were submerged in water, they soaked in water and within 1-2 s restored its original size and shape. Swelling degrees $(S), P / \%$ and $P_{\text {macropores }} / \%$ were calculated and given in Table 1 .
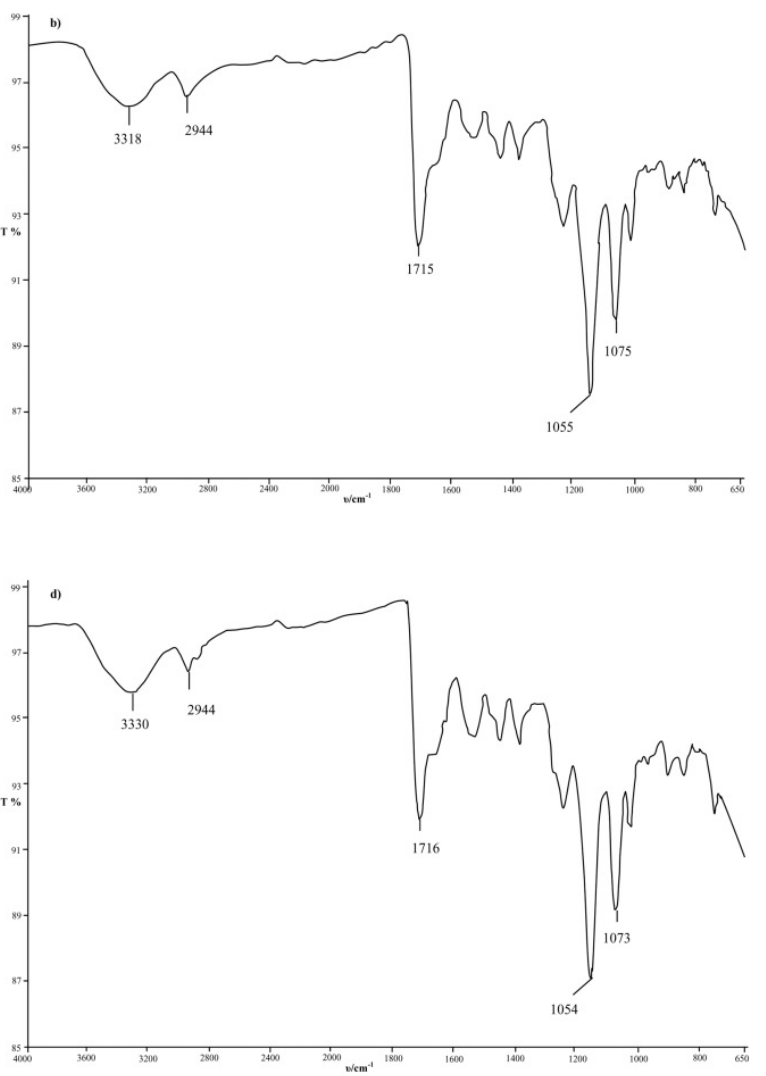

Figure 3. FTIR spectra of poly(HEMA) (a), poly(HEMA)-CB (b), poly(HEMA)-RG (c) and poly(HEMA)-RG (d) cryogel disks. 
Table 1. Swelling degree, $S$; porosity and porosity for macropores percentages for dye-attached cryogel disks

\begin{tabular}{lccc}
\hline & $S$ & $P / \%$ & $P_{\text {macropores }} / \%$ \\
\hline Poly(HEMA)-CB & 7.85 & 11.30 & 78.94 \\
Poly(HEMA)-RG & 5.86 & 14.59 & 65.66 \\
Poly(HEMA)-CR & 6.23 & 13.84 & 74.03 \\
\hline
\end{tabular}

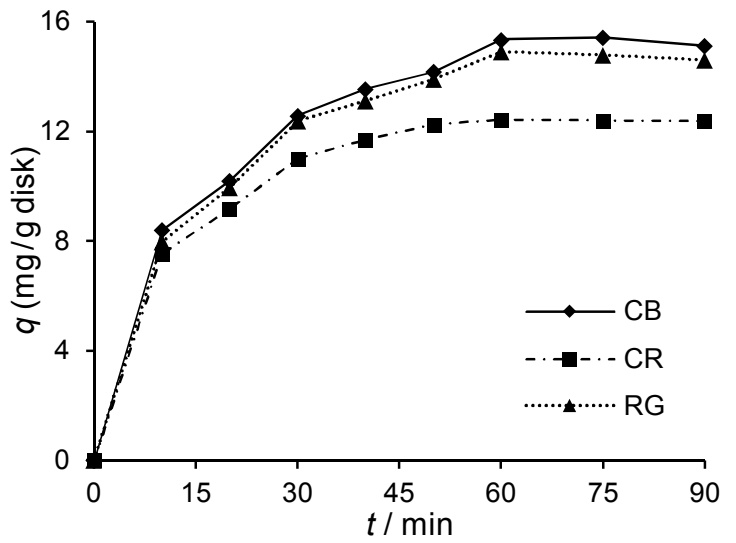

Figure 4. Effect of contact time on $\mathrm{Cd}^{2+}$ adsorption $(c=100$ $\mathrm{mg} / \mathrm{L}, \mathrm{pH}=7, \vartheta=25^{\circ} \mathrm{C}$ ).

\section{Optimization of $\mathrm{Cd}^{2+}$ Adsorption}

Effect of Contact Time

Adsorption studies were performed for different time periods until $90 \mathrm{~min}$. As shown in Figure 4, $\mathrm{Cd}^{2+}$ adsorption increased with time and reached a plateau of saturation at $60 \mathrm{~min}$. Therefore, all adsorption studies were performed at $60 \mathrm{~min}$ in further experiments.

\section{Adsorption Kinetics}

The kinetics of adsorption describes the rate of $\mathrm{Cd}^{2+}$ uptake and it controls the equilibrium time. The pseudofirst-order kinetic model has been widely used to predict adsorption kinetics. The model given by Langergren and Svenska $^{22}$ is defined as:

$$
\ln \left(q_{\mathrm{e}}-q_{t}\right)=\ln q_{\mathrm{e}}-k_{\mathrm{l}} t
$$

Where $q_{\mathrm{e}}$ and $q_{t}$ (in $\mathrm{mg} / \mathrm{g}$ ) are the amounts of $\mathrm{Cd}^{2+}$ adsorbed at equilibrium and at any time, $t(\mathrm{~h})$, and $k_{1}\left(\mathrm{~h}^{-1}\right)$ is the adsorption rate constant. When a graph of $\ln \left(q_{\mathrm{e}^{-}}\right.$ $\left.q_{t}\right) v s . t$ is drawn, a straight line with slope of $k_{1}$ and intercept of $\ln q_{\mathrm{e}}$ is obtained.

The pseudo-second-order equation ${ }^{23}$ based on equilibrium adsorption is expressed as:

$$
\frac{t}{q}=\frac{1}{k_{2} q_{\mathrm{e}}^{2}}+\frac{1}{q_{\mathrm{e}}}
$$

Where $k_{2}$ (in $\mathrm{g} / \mathrm{mg} \mathrm{h}$ ) is the rate constant. The linear plot of $t / q_{t} v s$. $t$ gives $1 / q_{\mathrm{e}}$ as the slope and $1 / k_{2} q^{2}{ }_{\mathrm{e}}$ as the intercept. This procedure is more likely to predict the behavior over the whole range of adsorption.

The Elovich equation, analyzed for applicability of adsorption data, is expressed as: ${ }^{24}$

$$
q_{t}=\left(\frac{1}{\beta}\right) \ln (\alpha \beta)+\frac{1}{\beta} \ln t
$$

Where $\alpha$ (in $\mathrm{mg} / \mathrm{g} \mathrm{h}$ ) is the initial adsorption rate and $\beta$ (in $\mathrm{g} / \mathrm{mg}$ ) is related to the extent of surface coverage. The parameters $(1 / \beta)$ and $(1 / \beta) \ln (\alpha \beta)$ can be obtained from the slope and intercept of the linear plot of $q_{\mathrm{t}}$ versus $\ln t$.

The value of $(1 / \beta)$ is indicative of the number of sites available for adsorption while the $(1 / \beta) \ln (\alpha \beta)$ is the adsorption quantity when $\ln t$ is equal to zero. This value is helpful in understanding the adsorption behavior of the first step. ${ }^{25}$ The $q_{\mathrm{e}}$ values calculated from Elovich equation agreed quite well with the experimental values.

As the above kinetic models were not able to identify the diffusion mechanism, thus intraparticle diffusion model based on the theory proposed by Weber and Morris ${ }^{26}$ was tested. It is an empirically found functional relationship, common to the most adsorption processes, where uptake varies almost proportionally with $t^{1 / 2}$ rather than with the contact time.

According to this theory:

$$
q_{t}=k_{\mathrm{pi}} t^{1 / 2}+c_{\mathrm{i}}
$$

Where $k_{\mathrm{p} i}$ (in $\mathrm{mg} / \mathrm{g} \mathrm{h}^{1 / 2}$ ), the rate parameter of stage $i$, is obtained from the slope of the straight line of $q_{t}$ versus $t^{1 / 2} . c_{i}$, the intercept of stage $i$, gives an idea about the thickness of boundary layer, i.e., the larger the intercept, the greater the boundary layer effect. It can be concluded from the data obtained that adsorption process was not controlled by intraparticle diffusion by the reason of correlation coefficient values.

All the correlation coefficient, $R^{2}$ values and constants obtained from the adsorption kinetics are given in Table 2. The correlation coefficient values for both the pseudo-first-order and the pseudo-second-order kinetic model are high $\left(R^{2}=0.9919\right.$ for poly(HEMA)-CB, $R^{2}=$ 0.9889 for poly(HEMA)-RG, $R^{2}=0.9623$ for poly(HEMA)-CR and $R^{2}=0.9931$ for poly(HEMA)-CB, $R^{2}=$ $R^{2}=0.9937$ poly(HEMA)-RG, $R^{2}=0.9962$ for poly(HEMA)-CR, respectively). Besides, calculated $q_{\mathrm{e}}$ values in both pseudo-first and pseudo-second order kinetic models are notably close to the experimental $q_{\mathrm{e}}$ values. Experimental data were rather accurately fitted onto both first-order and second-order kinetic models for cadmium adsorption. ${ }^{27,28}$ 
Table 2. Adsorption kinetic model constants and correlation coefficients for cadmium adsorption at $25^{\circ} \mathrm{C}$

\begin{tabular}{|c|c|c|c|c|c|}
\hline \multicolumn{6}{|c|}{ Pseudo-first-order kinetic model } \\
\hline & $q_{\text {e,exp. }}($ in $\mathrm{mg} / \mathrm{g}$ ) & \multicolumn{2}{|c|}{$q_{\mathrm{e}, \text { cal. }}($ in $\mathrm{mg} / \mathrm{g}$ ) } & $k_{1}($ in $1 / \mathrm{h})$ & $R^{2}$ \\
\hline Poly(HEMA)-CB & 15.36 & \multicolumn{2}{|c|}{11.64} & 2.78 & 0.9919 \\
\hline Poly(HEMA)-RG & 14.12 & \multicolumn{2}{|c|}{11.86} & 2.92 & 0.9889 \\
\hline Poly(HEMA)-CR & 12.44 & \multicolumn{2}{|c|}{13.80} & 4.79 & 0.9623 \\
\hline \multicolumn{6}{|c|}{ Pseudo-second-order kinetic model } \\
\hline & $q_{\mathrm{e}, \text { cal. }}$ (in $\mathrm{mg} / \mathrm{g}$ ) & $k_{2}($ in $\mathrm{g} / \mathrm{mg} \mathrm{h})$ & $t_{1 / 2}($ in $\min )$ & $h_{0.2}$ (in $\left.\mathrm{mg} / \mathrm{g} \min \right)$ & $R^{2}$ \\
\hline Poly(HEMA)-CB & 17.67 & 0.27 & 12.40 & 85.47 & 0.9931 \\
\hline Poly(HEMA)-RG & 17.48 & 0.26 & 10.58 & 80.00 & 0.9937 \\
\hline Poly(HEMA)-CR & 14.81 & 0.38 & 13.11 & 84.03 & 0.9962 \\
\hline \multicolumn{6}{|l|}{ Elovich equation } \\
\hline & $1 / \beta \ln (\alpha \beta)($ in $\mathrm{mg} / \mathrm{g})$ & $\alpha$ (in 1 & gh) & $\beta$ (in $\mathrm{g} / \mathrm{mg}$ ) & $R^{2}$ \\
\hline Poly(HEMA)-CB & 14.94 & & & 0.26 & 0.9793 \\
\hline Poly(HEMA)-RG & 14.66 & & & 0.26 & 0.9816 \\
\hline Poly(HEMA)-CR & 12.87 & & & 0.33 & 0.9856 \\
\hline \multicolumn{6}{|c|}{ Intra particle diffusion model } \\
\hline & $k_{\mathrm{p} i}\left(\right.$ in $\left.\mathrm{mg} / \mathrm{g} \mathrm{h}^{1 / 2}\right)$ & & $C_{i}$ & & $R^{2}$ \\
\hline Poly(HEMA)-CB & 0.85 & & 2.03 & & 0.9748 \\
\hline Poly(HEMA)-RG & 0.75 & & 1.99 & & 0.9778 \\
\hline Poly(HEMA)-CR & 0.90 & & 1.75 & & 0.9646 \\
\hline
\end{tabular}

Initial adsorption rates of poly(HEMA)-CB, poly(HEMA)-RG and poly(HEMA)-CR cryogel disks were calculated as $197.40 ; 176.79$ and $211.44 \mathrm{mg} / \mathrm{g} \mathrm{h}$, respectively, by using Elovich equation.

\section{Effect of $p H$}

The $\mathrm{pH}$ of solution is an important factor influencing complex formation and stability. Most chelating agents are unstable at low $\mathrm{pH}$, whereas at high $\mathrm{pH}$ metals tend to form insoluble hydroxides which are less accessible to chelating agents. ${ }^{29}$ The solubility of cadmium is governed by hydroxide or carbonate concentration. It is well known that precipitation of cadmium ions becomes significant at $\mathrm{pH}=8.5$. In order to establish the effect of $\mathrm{pH}$ on $\mathrm{Cd}^{2+}$ adsorption, studies were carried out at different $\mathrm{pH}$ in the range of 3.0-8.0.

As seen in Figure $5, \mathrm{Cd}^{2+}$ adsorption by dye attached $\mathrm{p}$ (HEMA) cryogel disks was low at $\mathrm{pH}=3.0$ due to protonation of the functional groups on the structure of dyes, but increased with increasing $\mathrm{pH}$. The increasing $\mathrm{pH}$ favors complex formation between the dye molecules and $\mathrm{Cd}^{2+}$ ions. Maximum adsorption was observed at $\mathrm{pH}=7.0$. In all solutions, hydronium ions $\left(\mathrm{H}_{3} \mathrm{O}^{+}\right)$and $\mathrm{Cd}^{2+}$ ions compete for adsorption. At low $\mathrm{pH}$ values, hydronium ions have high concentration and more tendencies to be adsorbed, so hydronium ions are adsorbed more than $\mathrm{Cd}^{2+}$ ions. ${ }^{30,31}$ Hydronium ions concentration decreases with increasing $\mathrm{pH}$, hence this decrease results in $\mathrm{Cd}^{2+}$ ions being better and more adsorbed. ${ }^{30-32}$. The reason of higher adsorption at higher $\mathrm{pH}$ values may also be that $\mathrm{Cd}^{2+}$ interact with $\mathrm{CB}$, $\mathrm{RG}$ and $\mathrm{CR}$ not only through the nitrogen and oxygen atoms by chelating, but also through $-\mathrm{SO}_{3} \mathrm{H}$ groups by cation-exchange, which is unprotonated at high $\mathrm{pH}$.

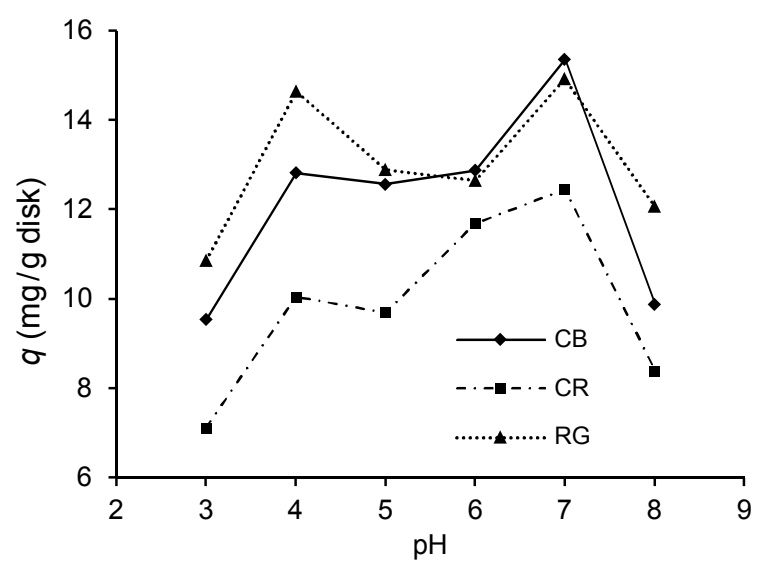

Figure 5. Effect of $\mathrm{pH}$ on $\mathrm{Cd}^{2+}$ adsorption ( $t=60 \mathrm{~min}, c=100$ $\left.\mathrm{mg} / \mathrm{L}, \vartheta=25^{\circ} \mathrm{C}\right)$. 


\section{Effect of Initial $\mathrm{Cd}^{2+}$ Concentration}

Figure 6 shows the effect of initial concentration. Maximum adsorption capacities were determined as 25.5 $\mathrm{mg} / \mathrm{g} ; 48.0 \mathrm{mg} / \mathrm{g}$ and $28.5 \mathrm{mg} / \mathrm{g}$ for poly(HEMA)-CB; poly(HEMA)-RG and poly(HEMA)-CR cryogel disks, respectively. While the adsorption capacities reached to a plateau value at about $200 \mathrm{mg} / \mathrm{L}$ for poly(HEMA)-CB and poly(HEMA)-CR; maximum adsorption capacity of poly(HEMA)-RG was determined at $400 \mathrm{mg} / \mathrm{L}$. These data demonstrates that $\mathrm{Cd}^{2+}$ adsorption capacity of poly(HEMA)-RG disks were higher than the others under the same conditions. Furthermore, non-specific $\mathrm{Cd}^{2+}$ adsorption on the poly(HEMA) cryogel disks was determined as negligibly small $(0.18 \mathrm{mg} / \mathrm{g})$. It can be concluded that dye immobilization increased the adsorbed $\mathrm{Cd}^{2+}$ amounts.

\section{Adsorption Isotherms}

The adsorption isotherm is the most important information indicating how the adsorbate molecules distribute between liquid and solid phase when the adsorption process reaches an equilibrium state. It is important to create the most appropriate correlation for the equilibrium curves to optimize the design of an adsorption system.

Langmuir isotherm assumes monolayer adsorption onto a surface containing a finite number of adsorption sites of uniform strategies of adsorption with no transmigration of adsorbate in the plane of surface. ${ }^{33}$ The linear form of Langmuir isotherm equation is given as:

$$
\frac{c_{\mathrm{e}}}{q_{\mathrm{e}}}=\frac{1}{L q_{\mathrm{m}}}+\frac{c_{\mathrm{e}}}{q_{\mathrm{m}}}
$$

Where, $q_{\mathrm{e}}$ is the amount of $\mathrm{Cd}^{2+}$ adsorbed per unit weight of disk at equilibrium (in $\mathrm{mg} / \mathrm{g}$ ) and $c_{\mathrm{e}}$ is the equilibrium concentration of $\mathrm{Cd}^{2+}$ in solution (in $\mathrm{mg} / \mathrm{L}$ ). $q_{\mathrm{m}}$ is the monolayer adsorption capacity (in $\mathrm{mg} / \mathrm{g}$ ) and $L$ is related with the adsorption energy (in $\mathrm{L} / \mathrm{mg}$ ). When $c_{\mathrm{e}} / q_{\mathrm{e}}$ is plotted against $c_{\mathrm{e}}$, a straight line with slope of $1 / q_{\mathrm{m}}$ and intercept of $1 / L q_{\mathrm{m}}$ is obtained.

The essential characteristics of Langmuir isotherm can be expressed by a dimensionless constant called equilibrium parameter, $R_{\mathrm{L}}$, defined by Weber and Chakkravorti ${ }^{33}$ as:

$$
R_{\mathrm{L}}=\frac{1}{1+L c_{0}}
$$

Where, $L$ is the Langmuir constant and $c_{0}$ is the highest initial $\mathrm{Cd}^{2+}$ concentration (in $\mathrm{mg} / \mathrm{L}$ ). $R_{\mathrm{L}}$ values bigger than 1 represent unfavorable, and between 0 and 1 represent favorable adsorption. Adsorption type is linear when $R_{\mathrm{L}}=1$ and irreversible when $R_{\mathrm{L}}=0$. Adsorption type can be commented as favorable at batch adsorption conditions due to $R_{\mathrm{L}}$ values were calculated between 0 and 1 .

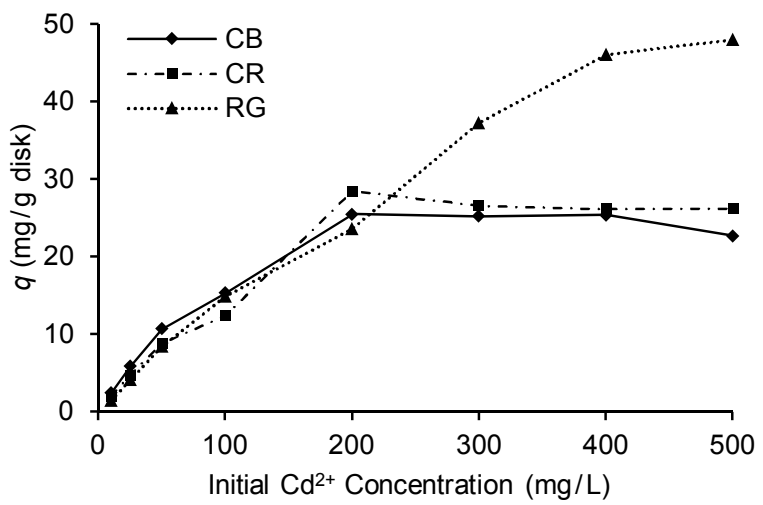

Figure 6. Effect of initial concentration on $\mathrm{Cd}^{2+}$ adsorption $\left(t=60 \mathrm{~min}, \mathrm{pH}=7, \vartheta=25^{\circ} \mathrm{C}\right)$.

Freundlich model is an empirical equation based on adsorption on a heterogeneous surfaces or surfaces supporting sites of varied affinities. It is assumed that the stronger binding sites are occupied first and the binding strength decreases with the increasing degree of site occupation. ${ }^{34}$ A linear form of the Freundlich expression can be presented as below:

$$
\log q_{\mathrm{e}}=\log K_{\mathrm{f}}+n_{\mathrm{f}} \log c_{\mathrm{e}}
$$

Where, $K_{\mathrm{F}}$ is the Freundlich constants giving the adsorption capacity and $n_{\mathrm{f}}$ is the Freundlich constants indicating favorability of the adsorption process. The plot of $\log q_{\mathrm{e}}$ versus $\log c_{\mathrm{e}}$ gave a straight line with slope of $n_{\mathrm{f}}$ and intercept of $\log K_{\mathrm{f}}$. The slope of $n_{\mathrm{f}}$ ranging between 0 and 1 is a measure of surface heterogeneity. The value of $n_{\mathrm{f}}$ below one indicates a normal Langmuir isotherm while $n_{\mathrm{f}}$ above one is indicative of cooperative adsorption. ${ }^{35}$

Temkin isotherm ${ }^{36}$ contains a factor that explicitly takes into account the adsorbent-adsorbate interactions. The adsorption is characterized by a uniform distribution of binding energies, up to some maximum binding energy. The Temkin isotherm is expressed as:

$$
q_{\mathrm{e}}=\left(\frac{R T}{b_{T}}\right) \ln \left(A c_{\mathrm{e}}\right)
$$

Where, $R T / b_{\mathrm{T}}=B$ (in $\mathrm{J} / \mathrm{mol}$ ), which is the Temkin constant related to heat of adsorption whereas $A$ (in $\mathrm{L} / \mathrm{g}$ ) is the equilibrium binding constant corresponding to the maximum binding energy. $R(8.314 \mathrm{~J} / \mathrm{mol} \mathrm{K})$ is the universal gas constant and $T$ (in $\mathrm{K}$ ) is the absolute solution temperature.

In order to calculate the mean free energy value of adsorption, Dubinin-Radushkevich (DR) isotherm has also been applied. The DR equation can be defined by the following equation: ${ }^{37}$

$$
\ln q_{e}=\ln X_{m}-\beta \varepsilon^{2}
$$


Where, $\beta$ is the constant related to sorption energy (in $\left.\mathrm{mol}^{2} / \mathrm{J}^{2}\right), X_{\mathrm{m}}$ is the Dubinin-Radushkevich monolayer capacity (in mol/g), $q_{\mathrm{e}}$ is the amount of adsorbed $\mathrm{Cd}^{2+}$ (in $\mathrm{mg} / \mathrm{g}$ ), $\varepsilon$ is the Polanyi potential which can be obtained as follows:

$$
\varepsilon=R T \ln \left(1+\frac{1}{c_{\mathrm{e}}}\right)
$$

Where, $c_{\mathrm{e}}$ is the equilibrium concentration of $\mathrm{Cd}^{2+}$ (in $\mathrm{mol} / \mathrm{L}), R$ gas constant $(8.314 \mathrm{~J} / \mathrm{mol} \mathrm{K})$ and $T$ the temperature (in $K$ ). By plotting $\ln q_{\mathrm{e}}$ versus $\varepsilon^{2}, \beta$ can be determined from the slope and $X_{\mathrm{m}}$ from the intercept. The mean free energy $E$ (in $\mathrm{kJ} / \mathrm{mol}$ ) of adsorption can be estimated by using $\beta$ values in the following equation:

$$
E=\frac{1}{(2 \beta)^{1 / 2}}
$$

All the correlation coefficients and the constants obtained from the four isotherm models applied for $\mathrm{Cd}^{2+}$ adsorption are given in Table 3 . In this work, the correlation obtained from the fitting of the Langmuir model was better than the fit using either the Freundlich or Temkin models. The result of the modeling therefore indicates monolayer sorption on a homogenous surface. Energy values ranging between 1 and $8 \mathrm{~kJ} / \mathrm{mol}$ indicate that the adsorption is due to physical interactions between adsorbent and adsorbate. ${ }^{38}$ The $E$ values between $7.00-7.45 \mathrm{~kJ} / \mathrm{mol}$ calculated from Equation 15 indicate that physisorption due to weak Van der Waals forces plays a significant role in the adsorption process.

\section{Effect of Temperature}

The adsorption studies were performed over a range of temperatures from 25 to $45{ }^{\circ} \mathrm{C}$. As seen in Figure 7, adsorption capacities of dye-attached cryogel disks decreased with increasing temperature. Except for the poly(HEMA)-CB cryogel disks, decrease at the adsorption capacity with increasing temperature is not statistically significant. This result can be explained by the exotermic nature of adsorption. ${ }^{39,40}$ Also, the decrease in adsorption capacity with increasing temperature could be derived from the increase in the average kinetic energy of $\mathrm{Cd}^{2+}$ ions. This increased kinetic energy causes insufficient attractive forces between $\mathrm{Cd}^{2+}$ ions and dyeattached p(HEMA) cryogel disks. ${ }^{41}$

\section{Thermodynamic Parameters}

Thermodynamic parameters such as Gibbs free energy change $\left(\Delta G^{\circ}\right)$, enthalpy change $\left(\Delta H^{\circ}\right)$, and entropy change $\left(\Delta S^{\circ}\right)$ were estimated for $\mathrm{Cd}^{2+}$ adsorption. $\Delta G^{\circ}$

\begin{tabular}{|c|c|c|c|c|c|}
\hline \multicolumn{6}{|l|}{ Langmuir Isotherm } \\
\hline & $q_{\mathrm{e}}($ in $\mathrm{mg} / \mathrm{g}$ ) & $L$ (in $\mathrm{L} / \mathrm{mg}$ ) & $q_{\mathrm{m}}($ in $\mathrm{mg} / \mathrm{g})$ & $R_{\mathrm{L}}$ & $R^{2}$ \\
\hline Poly(HEMA)-CB & 25.49 & 0.180 & 24.04 & 0.011 & 0.9917 \\
\hline Poly(HEMA)-RG & 48.06 & 0.023 & 63.29 & 0.080 & 0.9749 \\
\hline Poly(HEMA)-CR & 28.50 & 0.053 & 27.86 & 0.036 & 0.9918 \\
\hline \multicolumn{6}{|l|}{ Freundlich Isotherm } \\
\hline & $n_{\mathrm{f}}$ & \multicolumn{2}{|c|}{$K_{\mathrm{f}}($ in $\mathrm{mg} / \mathrm{g}$ ) } & \multicolumn{2}{|r|}{$R^{2}$} \\
\hline Poly(HEMA)-CB & 2.89 & \multicolumn{2}{|r|}{22.74} & \multicolumn{2}{|r|}{0.9089} \\
\hline Poly(HEMA)-RG & 1.59 & \multicolumn{2}{|r|}{7.03} & \multicolumn{2}{|r|}{0.9241} \\
\hline Poly(HEMA)-CR & 2.34 & \multicolumn{2}{|r|}{9.54} & \multicolumn{2}{|r|}{0.9494} \\
\hline \multicolumn{6}{|l|}{ Temkin Isotherm } \\
\hline & $\mathrm{A}($ in $\mathrm{L} / \mathrm{g}$ ) & \multicolumn{2}{|r|}{$\mathrm{B}$} & \multicolumn{2}{|r|}{$R^{2}$} \\
\hline Poly(HEMA)-CB & 2.30 & \multicolumn{2}{|r|}{3.83} & \multicolumn{2}{|r|}{0.9205} \\
\hline Poly(HEMA)-RG & 3.23 & \multicolumn{2}{|r|}{11.92} & \multicolumn{2}{|r|}{0.8767} \\
\hline Poly(HEMA)-CR & 1.02 & \multicolumn{2}{|r|}{4.68} & \multicolumn{2}{|r|}{0.8940} \\
\hline \multicolumn{6}{|c|}{ Dubinin-Redushkevich Isotherm } \\
\hline & $B\left(\right.$ in $\left.\mathrm{mol}^{2} / \mathrm{J}^{2}\right)$ & \multicolumn{2}{|c|}{$X_{\mathrm{m}}($ in $\mathrm{mg} / \mathrm{g}$ ) } & $E($ in $\mathrm{kJ} / \mathrm{mol})$ & $R^{2}$ \\
\hline Poly(HEMA)-CB & $9 \times 10^{-9}$ & \multicolumn{2}{|c|}{34.36} & 7.45 & 0.8277 \\
\hline Poly(HEMA)-RG & $1 \times 10^{-8}$ & \multicolumn{2}{|c|}{78.42} & 7.07 & 0.9682 \\
\hline Poly(HEMA)-CR & $9 \times 10^{-9}$ & \multicolumn{2}{|c|}{34.36} & 7.45 & 0.8214 \\
\hline
\end{tabular}

Table 3. Adsorption isotherm model constants and correlation coefficients for cadmium adsorption at $25^{\circ} \mathrm{C}$ 
values at different temperatures were calculated from the following equations:

$$
\begin{aligned}
& \Delta G^{\circ}=-R T \ln K_{\mathrm{d}} \\
& K_{\mathrm{d}}=\frac{q_{\mathrm{e}}}{c_{\mathrm{e}}}
\end{aligned}
$$

Where $q_{\mathrm{e}}$ is the amount of $\mathrm{Cd}^{2+}$ adsorbed at equilibrium (in $\mathrm{mg} / \mathrm{g}$ ), $c_{\mathrm{e}}$ is the equilibrium $\mathrm{Cd}^{2+}$ concentration (in $\mathrm{mg} / \mathrm{L}), K_{\mathrm{d}}$ is the distribution coefficient. $\Delta H^{\circ}$ is obtained from Van't Hoff equation:

$$
\ln K_{\mathrm{d}}=\frac{-\Delta H^{\circ}}{R T}+\frac{\Delta S^{\circ}}{R}
$$

Where $T$ is the absolute temperature, $R$ is gas constant $(8.314 \mathrm{~J} / \mathrm{mol} \mathrm{K}) . \Delta H^{\circ}$ and $\Delta S^{\circ}$ values were calculated from the slope and the intercept of the plot of $\ln K_{\mathrm{d}}$ versus $1 / T$. Calculated $\Delta H^{\circ}$ and $\Delta S^{\circ}$ values and also $\Delta G^{\circ}$ values at different temperatures are presented in Table 4.

As seen in Table 4, adsorption presented unfavorable $\Delta G^{\circ}$ values. On the other hand, all interactions presented exothermic enthalpy changes which suggest that $\mathrm{Cd}^{2+}$ adsorption by dye attached cryogel disks is thermodynamically favorable. It is supported by the decreasing adsorption of $\mathrm{Cd}^{2+}$ with the increase in temperature. The negative enthalpy values obtained with this study also shows that $\mathrm{Cd}^{2+}$ adsorption is a physisorption process. However, the adsorption was accompanied by a decrease of entropy. The negative entropy indicates a decrease in the randomness in the system solid/solution interface during the adsorption process. Thus, the adsorption was not favorable at higher temperatures.

\section{Desorption and Reusability Studies}

To prepare and use low cost and reusable adsorbents has a growing interest because of economical limitations. Desorption of $\mathrm{Cd}^{2+}$ from dye attached-p(HEMA) cryogel disks was performed in a batch system using different desorption agents with varying concentrations. Desorption ratio of $\mathrm{NaCl}$, 2-mercaptoethanol and thiourea of different concentrations are given in Figure 8.

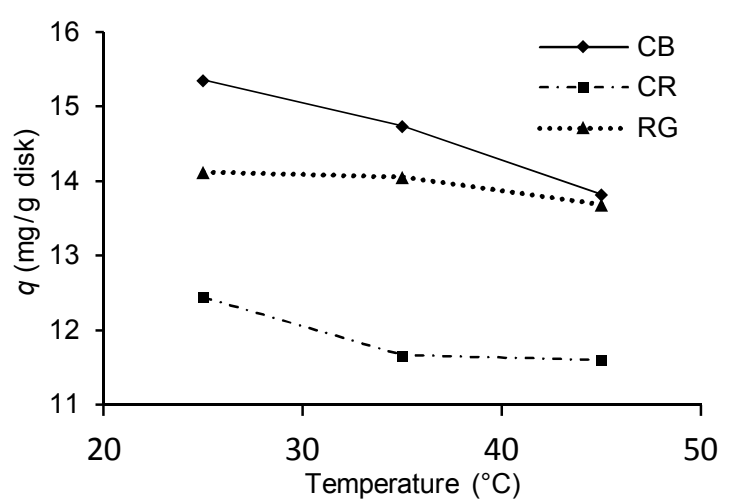

Figure 7. Effect of temperature on $\mathrm{Cd}^{2+}$ adsorption $(t=60$ $\min , \mathrm{pH}=7, c=100 \mathrm{mg} / \mathrm{L}$ )

It can be concluded that $1.0 \mathrm{M} \mathrm{NaCl}$ is a suitable desorption agent. Desorption values for $1.0 \mathrm{M} \mathrm{NaCl}$ were over than $90 \%$ for poly(HEMA)-CB and poly(HEMA)RG, but over than $95 \%$ for poly (HEMA)-CR.

In order to test reusability, adsorption-desorption cycle was repeated five times. Results showed that there was no remarkable decrease in the adsorption capacities of dye-attached cryogel disks and that these disks can be repeatedly used for $\mathrm{Cd}^{2+}$ removal.

\section{$\mathrm{Cd}^{2+}$ Ions Removal from Human Plasma}

Human plasma samples kept at $-20^{\circ} \mathrm{C}$ thawed for $1 \mathrm{~h}$ at $37{ }^{\circ} \mathrm{C}$ and diluted with buffer solution of $\mathrm{pH}=7.0$ at various dilutions. Samples were overloaded with 100 $\mathrm{mg} / \mathrm{L} \mathrm{Cd}^{2+}$ solution and disks were used in removal experiments under the optimum conditions. As seen in Figure 9, the most convenient dilution ratio for $\mathrm{Cd}^{2+}$ removal is 1:5. This result can be concluded that $\mathrm{Cd}^{2+}$ removal increases with increasing dilution due to decrease of shielding effect of blood components.

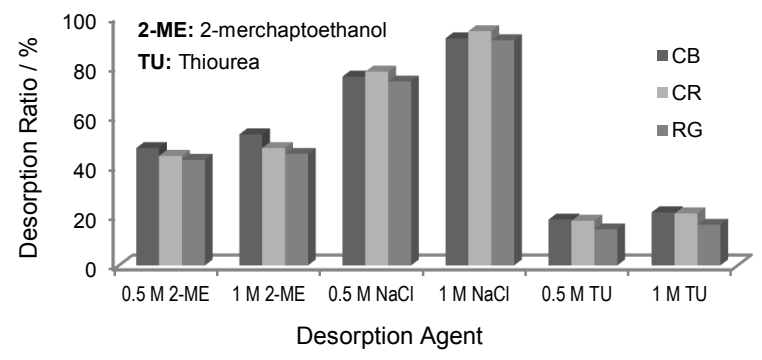

Figure 8. Desorption ratio of $\mathrm{Cd}^{2+}$ with desorption agents.

Table 4. Thermodynamic parameters for cadmium adsorption at $25^{\circ} \mathrm{C}$

\begin{tabular}{cccccc}
\hline & \multirow{2}{*}{$\Delta H^{\circ} / \mathrm{kJ} \mathrm{mol}^{-1}$} & $\Delta S^{\circ} / \mathrm{J} \mathrm{mol}{ }^{-1}$ & \multicolumn{3}{c}{$\Delta \mathrm{G}^{\circ} / \mathrm{kJ} \mathrm{mol}^{-1}$} \\
\cline { 5 - 6 } & & & $298 \mathrm{~K}$ & $308 \mathrm{~K}$ & $318 \mathrm{~K}$ \\
\hline Poly(HEMA)-CB & -8.15 & -31.85 & 1.29 & 1.78 & 1.92 \\
Poly(HEMA)-RG & -9.75 & -35.53 & 0.75 & 1.38 & 1.45 \\
Poly(HEMA)-CR & -7.01 & -29.18 & 1.57 & 2.22 & 2.13 \\
\hline
\end{tabular}




\section{CONCLUSION}

Attractive features of polymeric cryogels, that have excessive applications, make them appropriate chromatographic materials for various areas of biotechnology. Synthesized supermacroporous cryogel disks were modified with different textile dyes which are commercially available, inexpensive and having several reactive groups and incorporation of these dye ligands increased the adsorption capacity of the cryogel. Maximum $\mathrm{Cd}^{2+}$ adsorption of dye-attached cryogel disks was observed at $\mathrm{pH}=7$ and at $\vartheta=25{ }^{\circ} \mathrm{C}$ and $\mathrm{Cd}^{2+}$ adsorption capacity of poly(HEMA)-RG disks were higher than the others under these conditions. On the other hand, adsorption capacities of all of the dye-attached cryogel disks are quite well among the other adsorbents (Table 5). Langmuir model fitted better the experimental results, indicating monolayer adsorption on a homogenous surface. In addition, the adsorption energy, calculated by the Dubinin-Radushkevich equation, implied that the adsorption was dominated by the physical interactions between $\mathrm{Cd}^{2+}$ and dye attached $\mathrm{p}$ (HEMA) cryogel disks. The negative $\Delta H$ value indicated that the adsorption of $\mathrm{Cd}^{2+}$ onto the dye attached p(HEMA) cryogel disks was spontaneous. $\mathrm{Cd}^{2+}$ adsorption capacity of dye attached $\mathrm{p}$ (HEMA) cryogel disks decreased only $14 \%$ after five adsorption-

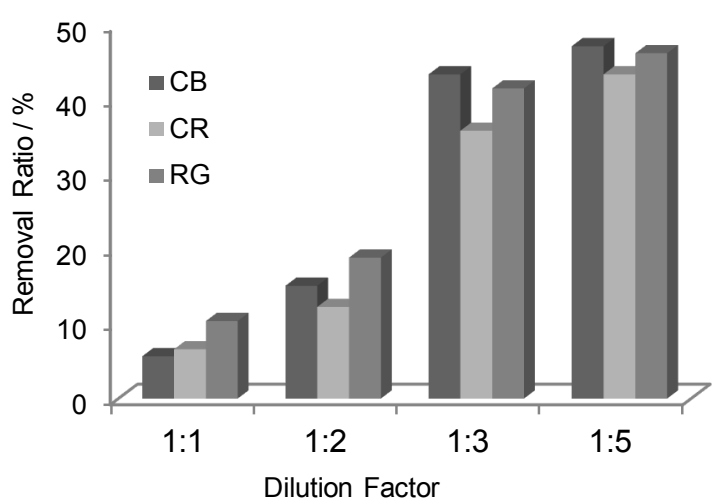

Figure 9. $\mathrm{Cd}^{2+}$ removal ratio of dye-attached cryogel disks from human plasma at various dilutions.

desorption cycles. Moreover, dye-attached cryogel disks were used for $\mathrm{Cd}^{2+}$ removal from overloaded human plasma samples. $\mathrm{Cd}^{2+}$ removal efficiencies of poly(HEMA)-CB; poly(HEMA)-RG and poly(HEMA)-CR cryogel disks from human plasma were determined as $47.18 \%$; $46.24 \%$ and $43.41 \%$, respectively. These results suggest that dye-attached poly(HEMA) cryogel disks, that are non-hazardous, easy to use and prepare, can be used for environmental and therapeutic applications.

Table 5. Adsorption capacities of different adsorbents for cadmium adsorption

\begin{tabular}{lcc}
\hline Adsorbent(s) used in the study & Q (in mg/g) & Ref. \\
\hline Indigenous clay & 0.5 & 42 \\
Coconut copra meal & 1.84 & 43 \\
Cd $^{2+}$ ion-imprinted superporous monolith & 3.00 & 8 \\
Cd $^{2+}$ ion-imprinted magnetic poly(HEMA-MAC) column & 5.48 & 5 \\
Chestnut shell & 5.57 & 44 \\
Oxidized granular activated carbon & 5.73 & 45 \\
Raw corn stalk/ corn stalk grafted acrylonitrile copolymer & $3.75 / 10.72$ & 46 \\
Bamboo charcoal & 12.08 & 47 \\
Coffee ground & 15.65 & 48 \\
Fe-montmorillonite/Ca-montmorillonite & $23.00 / 16.00$ & 4 \\
Urea-modified wheat straw & 39 & 49 \\
Poly(ethylene glycol dimethacrylate-n-vinyl imidazole) beads & 45.60 & 50 \\
Activated carbon derived from bagasse & 49.07 & 51 \\
Granular red mud & 52.10 & 52 \\
Chitosan activated carbon composite/ commercial activated carbon/chitosan & $52.63 / 10.30 / 10.00$ \\
Scolymus hispanicus L. & 54.05 & 53 \\
Olive leaves under ultrasound assistance & 62.18 & 52.20 \\
Dithiocarbamate-anchored polymer/organosmectite composites & 240 & 54 \\
Poly[4-(4-vinylbenzyloxy)-2-hydrobenzaldehyde] & 480 & 3 \\
Nano-poly (glycidyl methacrylate) cation exchange resin with sulphonate & 2000 & 55 \\
Poly(acrylamide) modified guar gum-silica nanocomposites & $25.5 / 48.0 / 28.5$ & 56 \\
poly(HEMA)-CB/poly(HEMA)-RG/poly(HEMA)-CR cryogel disks & & 57 \\
\hline
\end{tabular}




\section{REFERENCES}

1. E. Büyüktuncel, S. Bektas, Ö. Genç, and A. Denizli, React. Funct. Polym. 47 (2001) 1-10.

2. S. Vasudevan, and J. Lakshmi, Sep. Purif. Technol. 80(3) (2011) 643-651.

3. O. Hamdoui, Chem. Eng. Process. Process Intensif. 48(6) (2009) 1157-1166.

4. P. Wu, W. Wu, S. Li, N. Xing, N. Zhu, P. Li, J. Wu, C. Yang, and Z. Dang, J. Hazard. Mater. 169(1-3) (2009) 824-830.

5. N. Candan, N. Tuzmen, M., andac, C. A., andac, R. Say, and A. Denizli, Mater. Sci. Eng. C 29(1) (2009) 144-152.

6. B. Volesky, Biosorption of Heavy Metals, CRC Press, Boca Raton, FL, 1990, pp. 139-172.

7. M. P. Waalkes, J. Inorg. Biochem. 79 (2000) 241-244.

8. S. Aşır, L. Uzun, D. Türkmen, R. Say, and A. Denizli, Sep. Sci. Technol. 40 (2005) 3167-3185.

9. D. Horowitz, S. Margel, and T. Shimoni, Biomaterials 6 (1985) 9-16.

10. E. H. Ibrahim, A. Denizli, S. Bektaş, Ö. Genç, and E. Pişkin, J. Chromatogr. B 720 (1998) 217-224.

11. F. Denizli, Y. Arıca, and A. Denizli, React. Functl. Polym. 44 (2000) 207-217.

12. A. Denizli, B. Salih, and E. Pişkin, J. Biomater. Sci. Polym. Ed. 9 (1998) 175-187.

13. A. Denizli, H. Yavuz, C. Arpa, S. Bektas, and O. Genç, Sep. Sci. Technol. 38 (2003) 1869-1881.

14. V. Rebros, M. Rosenberg, Z. Mlichova, and L. Kristofikova, Food Chem. 102 (2007) 784-787.

15. V. I. Lozinsky, F. M. Plieva, I. Y. Galaev, and B. Mattiasson, Bioseparation 10 (2002) 163-188.

16. V. I. Lozinsky, I. Y. Galaev, F. M. Plieva, I. N. Savina, H. Jungvid, and B. Mattiasson, Trends Biotechnol. 10 (2003) 445-451.

17. A. Denizli, and E. Pişkin, J. Biochem. Biophys. Methods 49 (2001) 391-416

18. G. T. Hermanson, A. K. Mallia, P. K. Smith, Immobilized Affinity Ligand Techniques, Academic Pres Inc, California, USA, 1992, pp. 174-176.

19. F. M. Plieva, I. N. Savina, S. Deraz, J., andersson, I. Y. Galaev, and B. Mattiasson, J. Chromatog. B 807 (2004) 129-137.

20. F. M. Plieva, M. Karlsson, M. R. Aguilar, D. Gomez, S. Mikhalovsky, and I. Y. Galaev, Soft Mater. 1 (2005) 303-309.

21. D. Horak, F. Lednick, and M. Bleha, Polymer 37 (1996) 4243 4249.

22. S. Langergren, and B. K. Svenska, Veternskapsakad Handlingar 24(4) (1898) 1-39.

23. Y. S. Ho, and G. McKay, Can. J. Chem. Eng. 76 (1998) 822 826.

24. M. Ozacar, and I. A. Sengil, Process Biochem. 40 (2005) 565-572.

25. R. L. Tseng, J. Colloid Interface Sci. 303 (2006) 494-502.

26. W. J. Weber, J. C. Morris in: Proc. Int. Conf. Water Pollution Symposium, vol. 2, Pergamon, Oxford, 1962, pp 231-266.

27. M. R. Samarghandi, M. Zarrabi, A. Amrane, M. N. Sepehr, M. Noroozid, S. Namdari, and A. Zarei, Desal. Water Treat. 40 (2012) 137-143.

28. S. M. Silva, K. A. Sampaio, R. Ceriani, R. Verhé, C. Stevens, W. D. Greyt, and A. J. A. Meirelles, J. Food Eng. 118 (2013) 341-349.
29. S. J. S. Flora, and V. Pachauri, Int. J. Environ. Res. Public Health 7 (2010) 2745-2788.

30. B. Erdem, A. Özcan, Ö. Gök, and A. S. Özcan, J. Hazard. Mater. 163 (2009) 418-426.

31. O. Moradi, M. Aghaie, K. Zarea, M. Monajjemi, H. Aghai, J. Hazard. Mater. 170 (2009) 673-679.

32. Y. Xue, H. Houa, S. Zhu, J. Hazard. Mater. 162 (2009) 391401.

33. T. W. Weber, and R. K. Chakkravorti, AIChE J. 20 (1974) 228 238.

34. H. M. F. Freundlich, J. Phys. Chem. 57 (1906) 385-470.

35. A. Altınışık, E. Gür, and Y. Seki, J. Hazard. Mater. 179 (2010) 658-664.

36. M. I. Temkin, V. Pyzhev Acta Physiochim. URSS 12 (1940) 327-356.

37. M. M. Dubinin, L. V. Radushkevich Proc. Acad. Sci. USSR 55 (1947) 331-333.

38. J. M. Smith, Chemical Engineering Kinetics, McGraw-Hill, New York, 1981, p. 676.

39. Y. A. Aydin, and N. D. Aksoy, Chem. Eng. J. 151 (2009) 188 194.

40. V. K. Gupta, I. Ali, and V. K. Saini, J. Colloid Interface Sci. 315 (2007) 87-93.

41. N. Sangiumsak, P. Punrattanasin, Pol. J. Environ. Stud. 23 (2014) 853-865.

42. Y. C. Sharma, Chem. Eng. J. 145 (2008) 64-68.

43. A. E. Ofomaja, and Y. S. Ho, J. Hazard. Mater. 139 (2007) 356362 .

44. G. Vázquez, M. Sonia Freire, J. González-Alvarez, and G. Antorrena, Desalination 249 (2009) 855-860.

45. H. Xin, G. Nai-yun, and Z. Qiao-li. J. Environ. Sci. 19 (2007) 1287-1292.

46. L. Zheng, Z. Dang, C. Zhu, X. Yi, H. Zhang, and C. Liu, Bioresource Technol. 101 (2010) 5820-5826.

47. F. Y. Wang, H. Wang, and J. W. Ma, J. Hazard. Mater. 177 (2010)300-306.

48. N. Azouaoua, Z. Sadaoui, A. Djaafri, and H. Mokaddem, J. Hazard. Mater. 184 (2010) 126-134.

49. U. Farooq, M. A. Khan, M. Athar, and J. A. Kozinskia, Chem. Eng. J. 171 (2011) 400-410.

50. A. Kara, L. Uzun, N. Beşirli, and A. Denizli, J. Hazard. Mater. 106B (2004) 93-99.

51. D. Mohan, and K. P. Singh, Water Res. 36 (2002) 2304-2318.

52. C. Zhua, Z. Luana, Y. Wang, and X. Shan, Sep. Purif. Technol. 57 (2007) 161-169.

53. S. Hydari, H. Sharififard, M. Nabavinia, and M. Parvizi, Chem. Eng. J. 193-194 (2012) 276-282.

54. N. Barka, M. Abdennouri, A. Boussaoud, and M. Makhfouk. Desalination 258 (2010) 66-71.

55. R. Say, E. Birlik, A. Denizli, and A. Ersöz, Appl. Clay Sci. 31 (2006) 298-305

56. P. A. Amoyaw, M. Williams, and X. R. Bu, J. Hazard. Mater. 170(1) (2009) 22-26.

57. M. F. Elkady, M. A. Abu-Saied, A. M. A. Rahman, E. A. Soliman, A. A. Elzatahry, M. E. Yossef, and M. S. M. Eldin, Desalination 279 (2011) 152-162.

58. V. Singha, S. Pandeya, S. K. Singha, and R. Sanghib, Sep. Purif. Technol. 67 (2009) 251-261 